Marquette University

e-Publications@Marquette

3-2017

\title{
Health Effects of Adverse Childhood Events: Identifying Promising Protective Factors at The Intersection of Mental and Physical Well-Being
}

Victoria Banyard

University of New Hampshire, Durham

Sherry L. Hamby

Sewanee: The University of the South

John H. Grych

Marquette University, john.grych@marquette.edu

Follow this and additional works at: https://epublications.marquette.edu/psych_fac

Part of the Psychology Commons

\section{Recommended Citation}

Banyard, Victoria; Hamby, Sherry L.; and Grych, John H., "Health Effects of Adverse Childhood Events: Identifying Promising Protective Factors at The Intersection of Mental and Physical Well-Being" (2017). Psychology Faculty Research and Publications. 346.

https://epublications.marquette.edu/psych_fac/346 


\section{Marquette University \\ e-Publications@Marquette}

\section{Psychology Faculty Research and Publications/College of Arts and Sciences}

This paper is NOT THE PUBLISHED VERSION; but the author's final, peer-reviewed manuscript. The published version may be accessed by following the link in the citation below.

Child Abuse \& Neglect, Vol. 65 (March, 2017): 88-89. DOI. This article is (c) Elsevier and permission has been granted for this version to appear in e-Publications@Marquette. Elsevier does not grant permission for this article to be further copied/distributed or hosted elsewhere without the express permission from Elsevier.

\section{Health Effects of Adverse Childhood Events: Identifying Promising Protective Factors at the Intersection of Mental and Physical Well-being}

Victoria Banyard

University of New Hampshire

Sherry Hamby

Sewanee University of the South

John Grych

Marquette University

Keywords

Adverse childhood events, Resilience, Health quality of life

\section{Abstract}

Research documents how exposure to adversity in childhood leads to negative health outcomes across the lifespan. Less is known about protective factors - aspects of the individual, family, and community that promote good health despite exposure to adversity. Guided by the Resilience Portfolio Model, this study examined protective factors associated with physical health in a sample of adolescents and adults 
exposed to high levels of adversity including child abuse. A rural community sample of 2565 individuals with average age of 30 participated in surveys via computer assisted software. Participants completed self-report measures of physical health, adversity, and a range of protective factors drawn from research on resilience. Participants reporting a greater burden of childhood victimization and current financial strain (but not other adverse life events) had poorer physical health, but those with strengths in emotion regulation, meaning making, community support, social support, and practicing forgiveness reported better health. As hypothesized, strengths across resilience portfolio domains (regulatory, meaning making, and interpersonal) had independent, positive associations with health related quality of life after accounting for participants' exposure to adversity. Prevention and intervention efforts for child maltreatment should focus on bolstering a portfolio of strengths. The foundation of the work needs to begin with families early in the lifespan.

\section{Introduction}

Decades of research now make clear that exposure to adverse events in childhood is associated with a range of negative physical and mental health outcomes (Banyard et al., 2008Banyard, Edwards, \& Kendall-Tackett, 2008; Shonkoff \& Garner, 2012). These events include child maltreatment, witnessing violence, having family members with substance use problems, but also an array of other forms of youth victimization including bullying (Finkelhor, Shattuck, Turner, \& Hamby, 2013; Finkelhor, Turner, Ormrod, \& Hamby, 2009). Exposure to greater adversity is associated with negative outcomes that range from increased perpetration of violence in adolescence (Duke, Pettingell, McMorris, \& Borowsky, 2010) to emotional distress (Briggs-Gowan, Carter, \& Ford, 2012; Norman et al., 2012; Tucker, Finkelhor, Turner, \& Shattuck, 2013; Turner, Finkelhor, Shattuck, \& Hamby, 2012) to physical health problems (Del Gaizo, Elhai, \& Weaver, 2011; Flaherty et al., 2013, Hager and Runtz, 2012; Widom, Czaja, Bentley, \& Johnson, 2012). These associations have been found using both crosssectional and longitudinal designs using a variety of samples including older adults, ethnically diverse samples, military personnel, and (Maschi, Baer, Morrissey, \& Moreno, 2013; Merskya, Topitzesb, \& Reynolds, 2013; Sareen et al., 2013). The importance of this link is highlighted by Shonkoff, Garner, Fa, Depe, and Pediat (2012) who state, "many adult diseases should be viewed as developmental disorders that begin early in life." They urge a lifespan perspective on the impact of childhood trauma (Afifi, Mota, MacMillan, \& Sareen, 2013) for example, one type of adverse event, harsh physical punishment in childhood, was associated with increased odds of several diseases in adulthood including cardiovascular problems. Healthcare and mental health professionals can play a key role in addressing and seeking to prevent these problems by attending to opportunities to reduce stress and stress responses but also to promote buffering processes that may protect individuals (Garner et al., 2012, Sege and Linkenbach, 2014, Shonkoff and Garner, 2012). To date, however, we know far less about protective factors and resilience.

A number of definitions have been used in research on resilience (Masten, 2014, Sabina and Banyard, 2015; Southwick, Bonanno, Masten, Panter-Brick, \& Yehuda, 2014). It has been described as an outcome where an individual shows some high level of functioning following a significant adversity or trauma. It has also been described as a process of adaptation such that an individual is able to recover positive physical or mental health after adversity (Masten, 2014) or demonstrate a steady state of mental health through periods of exposure to stress 
(Southwick et al., 2014). Researchers have often studied resilience in terms of its correlates, or what are termed protective factors, assets, or resources. These are the variables within an individual or her or his social network or community that help promote this well-being in the face of adversity. The current study uses a model, described in more detail below, that draws and seeks to integrate all of these lines of inquiry.

While researchers in child development have long been at the forefront of work in resilience science, child maltreatment researchers more specifically have shown increasing attention to this topic (Afifi \& MacMillan, Tanaka, Duku, Vaillancourt, \& Boyle, 2013; Cicchetti, 2013). For example, a review by Afifi and MacMillan (2011) described factors related to resilience across the ecological model. They highlighted the importance of personality factors like self esteem and easy temperament and the key role of interpersonal relationships especially those within the family for resilience. They noted that most research on this topic has focused on samples of children rather than investigating adult survivors of childhood maltreatment. A review focused more specifically on child sexual abuse created a long list of factors including optimism and hope, coping skills and sense of control and community social support (Marriott, Hamilton-Giachritsis, \& Harrop, 2014) while work by Ungar, 2013a, Ungar, 2013b highlighted the need to also attend to cultural contexts that may affect both how markers of resilient functioning manifest themselves and the mechanisms for promoting it. Indeed, a special issue of the journal Child Abuse and Neglect in 2013 was devoted to studies examining factors related to more positive outcomes among maltreated children and adolescents (Ungar, 2013a, Ungar, 2013b, Wolfe, 2013).

A number of limitations have been noted, however, and much remains to be learned about resilience in the context of adverse childhood experiences (Cicchetti, 2013). Sabina and Banyard (2015) discussed the need for violence researchers to look at combinations of protective factors related to resilient functioning rather than studies that focus on one at a time. A recent study by Lenzi et al. (2015) on school victimization among high school students found that the quantity of assets (including self-efficacy, social support and positive family relationships, optimism, emotional regulation) an individual reported (for example having four to nine assets) seemed to create an important tipping point for protecting against victimization. They also found that the variety of domains of protective factors (collections of types of factors) was also important. Youth with at least one asset in different domains (believing in self, engaged living) had better outcomes. Studies are needed that examine more than one protective factor at a time. Researchers have also called for an expanded lifespan perspective, engaging participants beyond childhood and adolescence to understand patterns of resilient functioning (Sabina \& Banyard, 2015). The current study employed a large community survey to investigate resilience across adolescence and adulthood.

Work by Ungar, 2013a, Ungar, 2013b and Masten (2014) discussed how resilience may look different in various cultural contexts. This reminds us of the importance of studying resilience across cultural and geographic locations as well. Geography has been important to understanding risk for child maltreatment. MacMillian et al. (2013) found urban residence was a risk factor for child maltreatment. Other studies described high rates of family violence such as intimate partner violence in rural communities (Rennison, DeKeseredy, \& Dragiewicz, 2013), noting how aspects of stress and isolation that are part of rural life may enhance risk for 
child maltreatment (Rosenberg \& Reppucci, 1983). We might also expect differences between rural and urban locations in resilience, though this has been less studied. For example, extended kin networks and strong family ties found in some rural communities may be a protective factor against victimization (Rosenberg \& Reppucci, 1983). Further, several studies have documented unique ways that individuals in rural areas in the United States and abroad define terms like "health" or "resilience" (Gessert et al., 2015, Hegney et al., 2007). Rural residents were more likely than urban residents to value self-reliance, spiritual health, and health as the ability to work and fulfill social roles (Gessert et al., 2015, Woodard, 2011). Focus groups on women's health by Leipert and George (2008) highlighted the importance of rural risk and protective factors. For example, a key source of rural stress was related to changes in rural communities related to farms and income, while local pride in being able to solve problems within their community, and values of caring for neighbors were noted as potentially protective. The current study sought to examine resilience in a rural context. Thus, we examined a sample of participants that faced particular challenges to resilience including poverty and lower access to health services, and also unique potential protective factors including spirituality, community ties, and perseverance. Child maltreatment in rural contexts remains an understudied topic but an important context for broadening our understanding of resilience in various contexts.

The Resilience Portfolio model (Grych, Hamby, \& Banyard, in press) integrates research in psychology on resilience, thriving, and character strengths. It provides a framework for research to support these next steps in research. Such research can then serve as a platform for "protective interventions" (Garner et al., 2012) that promote well-being not just by reducing risk but by promoting competence even in the face of significant adversity. It draws from recent work on better defining resilience and the protective factors that may lead to it (Benavides, 2015, Southwick et al., 2014). The portfolio model draws from definitions of resilience as an outcome and a process. For example, the model moves beyond defining the outcome resilience as the absence of problems or mental health symptoms to promoting the use of measures of the presence of well-being as the outcome in statistical models. Consistent with a process model, it also provides an organizing framework for considering multiple protective factors that may contribute to resilience at the same time and that may be a focus of specific prevention and intervention strategies. These protective factors or strengths are drawn from across the ecological framework of individuals, families, communities, and society. Resources are defined as protective factors that are outside of the person that support positive functioning including social supports and positive community factors like collective efficacy. Assets are the term used to refer to what violence researchers often refer to as protective factors, and researchers in positive psychology call strengths. They are characteristics that are associated with well-being across the lifespan. Three key areas of assets are described. Regulatory strengths and resources include constructs like emotion regulation, coping skills and endurance or persistence in the face of obstacles. Meaning-making strengths and resources include sense of purpose and mattering, meaning making activities, and religious based coping. Interpersonal strengths and resources include social support, community support, generosity to others and forgiveness. Similar to work by Lenzi et al. (2015) and Schnell (2011), the resilience portfolio model emphasizes the importance of poly-strengths, that no one particular asset or resource is expected to be a driver of resilient outcomes, rather it may be 
the total constellation of assets and resources that one has that promotes better functioning after adversity.

The aim of the current project was to begin to test the resilience portfolio model and its utility for looking at the functioning of individuals experiencing a high lifetime adversity burden. We examined the role of strengths and resources in the association of childhood victimization with lifelong health related quality of life in a community sample residing in the cultural context of rural Appalachia. While scholars caution against the use of stereotypical or overly restrictive characterizations of a region or culture (Obermiller \& Maloney, 2016), research documents that the region does faces challenges of poverty and less access to formal healthcare and other services. These stresses contribute to the adversity burden of individuals who live in this region over and above exposure to traumas like child maltreatment. The region also has important cultural strengths that are important to examine as part of individuals' resilience portfolios. These include attachment to their region, strong sense of spirituality and religion, sense of community and community helping (Gore, Sheppard, Waters, Jackson, \& Brubaker, 2016; Woodard, 2011).

While the promise of resilience as a construct is that it is a strength based lens, this promise is often not realized in research questions and measures that are focused on the inverse of risk. Further, protective factors are often studied one at a time. We hypothesized that individuals who were exposed to greater adversity would report lower health quality. However, we also hypothesized that possessing a range of strengths across the competency domains described above would be linked to good quality physical health related quality of life.

\section{Method}

\subsection{Participants}

Participants were 2565 participants from the Appalachian region of 3 Southern states. The sample was $63.9 \%$ female. The sample included adolescents and adults age 12 and over, with an average age of 30.0 years (standard deviation 13.2) and a median of 27. Educational status included $18.1 \%$ who were still in middle or high school, $34.8 \%$ who had a high school diploma or equivalent, $7.2 \%$ with less than a high school education (and not currently in school), $18.6 \%$ with some college but no degree, $8 \%$ with an associate's degree, $7.9 \%$ with a bachelor's degree, and $5.4 \%$ with more than a bachelor's degree. Almost 2 in $5(39.2 \%)$ of the sample reported household income less than $\$ 20,000$ per year, 36\% earned $\$ 20,000-\$ 50,000$, and $24.9 \%$ of the sample earned more than $\$ 50,000$ per year. The sample identified as $75.6 \%$ White/European-American (non-Latino), 12\% Black/African-American (non-Latino), 6.4\% Latino (any race), 1.2\% American Indian/Alaska Native, 0.6\% Asian, 0.3\% Pacific Islander, and $3.9 \%$ multiracial.

\subsection{Measures}

\subsubsection{Development and validation of measures in pilot study and this sample}

Given that our sample included significant numbers of young adolescents and people with limited educational attainment, it was essential that the reading level be appropriate for all 
participants. Brevity was also a priority. We simplified and adapted items from existing questionnaires and wrote new items for constructs for which no suitable measure could be found.

To establish reliability and validity for new and adapted items, we conducted a pilot study with 108 participants from the same community as the main sample, recruited through a local email classifieds list and word-of-mouth. Reliability and validity were further examined in this sample. Internal consistencies for the pilot and main samples are in Table 1. Validity was established in the pilot and main samples with moderate correlations with related constructs. Further details on each measure are below. Unless specified, response categories were on a 4-point Likert scale with 1 denoting "Not true about me" and 4 denoting "Mostly true about me." Standardizing response categories across items reduces the respondent burden, shortens survey time, and minimizes method variance and is common for large scale community surveys (e.g., Finkelhor, Turner, Hamby, \& Ormrod, 2011; Finkelhor, Shattuck, Turner, \& Hamby, 2014). In all cases, higher scores represent higher levels of strengths, psychological functioning, and adversity. See http://lifepathsresearch.org for complete scales further details on measure development. Also see Hamby, Thomas, Banyard, de St. Aubin, and Grych (2015) and Roberts, Hamby, Grych, and Banyard (2015).

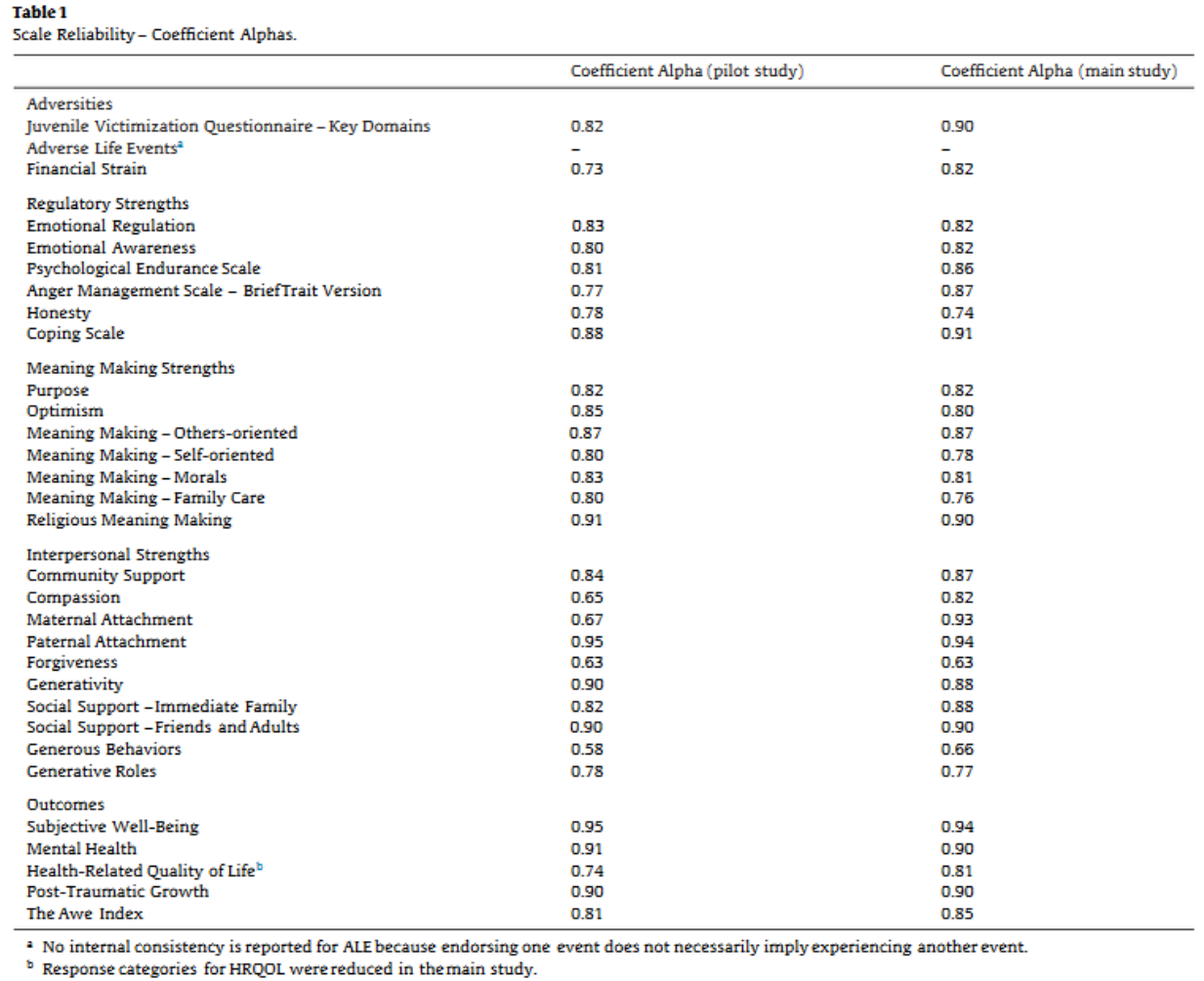

Adversities included three broad domains - interpersonal victimization (adapted from Finkelhor, Hamby, Ormrod, \& Turner, 2005), adverse life events (H. Turner, Shattuck, Hamby, \& Finkelhor, 2013), and financial strain (Hamby, Turner, \& Finkelhor, 2011). The Juvenile Victimization Questionnaire - Key Domains Form includes 20 items assessing lifetime history of a range of interpersonal victimizations. A sample item was "During your childhood, did one 
of your parents get hit or pushed by another parent?" Dichotomous items ("yes" or "no") were summed to create a total victimization score. This measure has demonstrated excellent reliability and validity in previous research. An 11-item scale adapted from NatSCEV (Turner et al., 2013) measured the types of major life challenges one has experienced and was used as a broader measure of stress and adversity burden. Responses were dichotomous, and "yes" answers were summed to create a total score. A sample item was "Did you ever have anyone close to you die because of an illness or an accident?" Because endorsing one event does not necessarily imply experiencing another event, no internal consistency is reported. Financial Strain. Five items assessing perceived economic pressure were also included in the survey (Hamby et al., 2011). A sample item was 'You don't have enough money to pay regular bills.' Participants responded on a 3-point Likert scale from "Not true" to Very true."

\subsubsection{Strengths}

A range of protective strengths were assessed representing areas specified by the Resilience Portfolio Model. Higher scores indicated greater functioning and strengths were measured on a continuous scale.

Regulatory strengths assessed various aspects of self-control, especially when confronting difficulties. Emotional Regulation included 4 items assessing one's ability to manage distressing feelings adapted from the DERS (Gratz \& Roemer, 2004). A sample (reversescored) item was "When I'm upset, I feel out of control." Emotional Awareness was assessed with 2 items on the ability to monitor one's own feelings adapted from the DERS (Gratz \& Roemer, 2004). A sample item was "I am aware of my feelings." The Psychological Endurance Scale (Hamby, Banyard, \& Grych, 2013) was made up of 6 items to assess one's ability to persist in the face of challenges. A sample item was "I am quick to pick myself up when I get "knocked down." The Anger Management Scale-Brief Trait Version (Hamby, Stith, Grych, \& Banyard, 2013) was made up of 5 items describing the ability to control one's temper adapted from Stith and Hamby's (2002) partner-specific scale. A sample item was "I can calm myself down when I am upset." Honesty used 2 items adapted from the HEXACO-PI-R (Ashton \& Lee, 2009) to assess ethical behavior. A sample (reverse-scored) item was "If I knew that I could never get caught, I might be willing to steal." The Coping Scale (Hamby, Banyard et al., 2013) consisted of 13 items designed to describe behavioral and cognitive-emotional responses an individual might use when dealing with adversity (partially adapted from Holahan and Moos, 1987, Spitzberg and Cupach, 2008). A sample item was "When dealing with a problem, I spend time trying to understand what happened."

Meaning making constructs assessed ways that individuals seek spiritual and personal fulfilment. The Purpose scale included 2 items from the Meaning in Life Questionnaire (Steger, Frazier, Oishi, \& Kaler, 2006) and 1 item from the Life Orientation Test (Scheier, Carver, \& Bridges, 1994) that assessed perceptions that there is a reason for existence. A sample item was "I have a good sense of what makes my life meaningful." Optimism. Two items from the Life Orientation Test (Scheier et al., 1994) measured positive expectancies, e.g., "I hardly ever expect things to go my way" (reverse-scored). Meaning Making Questionnaire (Banyard, Hamby, \& Grych, 2013; Hamby et al., 2015) The Meaning Making Questionnaire included 4 subscales and was adapted from work by Schnell (2011) but designed to describe behaviors 
and actions related to mattering and pursuing purpose in life. Meaning-Making - Othersoriented included 10 items on how individuals help others to make their own lives meaningful. A sample item was "I work hard to be an active member of my community." Meaning Making Self-oriented included 8 items on improving one's mental and physical well-being as a way of finding purpose. A sample item was "I spend time each week learning something new." Meaning Making - Morals assesses adherence to standards of beliefs and behaviors in respondents' daily lives (4 items). A sample item was "I make sure that each day I am doing the right thing." Meaning Making - Family Care. Five items measured caregiving and actions focused on strengthening family ties as a way of finding meaning. A sample item is "I take care of older or younger family members each week." Religious Meaning Making. This scale consisted of 11 items (Amato, 1990; Levin, Markides, \& Ray, 1996; Pargament, Koenig, \& Perez, 2000; Pargament, Smith, Koenig, \& Perez, 1998; Putney \& Middleton, 1961) assessing engagement in religious and spiritual practices. A sample item was "My faith or spiritual beliefs affect my views on other things."

Interpersonal strengths included the participants' relational skills and also indicators of support from their larger social environment. Community Support. Nine items assessed collective efficacy or the degree to which one's neighbors get along and helps one another (Roberts et al., 2015; adapted from Sampson, Raudenbush, \& Earls, 1997; from U.S. Air Force, 2011). A sample item was "People in my neighborhood offer help to one another in times of need." Compassion. Seven items assessed how connecting with others in a caring, concerned, and helpful way (partially adapted from McCullough, Emmons, \& Tsang, 2002; Pommier, 2011, Sprecher and Fehr, 2005). A sample item was "When others feel sad, I try to comfort them." Maternal Attachment. Six behavioral indicators of a close and secure relationship with one's mother or mother figure, adapted from the Attachment Behaviors Scale (Furman \& Buhrmester, 2009). A sample item was "You seek out your mother (or mother figure) when you're upset." Paternal Attachment. Parallel items to maternal attachment asked about one's father or father figure. Nine items were included that measured closeness and security one generally feels in intimate relationships, adapted from the partner-specific Experiences in Close Relationships Questionnaire (Fraley, Waller, \& Brennan, 2000). A sample (reversescored) item was "I worry a lot about my relationships." (adapted from Fraley et al., 2000, Gordon and Baucom, 2003, Norton, 1983). A sample item was "My partner and I are really a team." Forgiveness was assessed with three items describing one's ability to move on following an argument (adapted from the partner-specific scale developed by Gordon \& Baucom, 2003). A sample item was "I am ready to put what happened behind me." Generativity. Five items adapted from the Loyola Generativity Scale - Short Form (McAdams \& de St. Aubin, 1992) measuring one's concern for guiding future generations. A sample item was "I like to teach things to people." Workplace Integration. Four items assessed cohesion among one's coworkers and professional investment (Roberts et al., 2015; adapted from U.S. Air Force, 2011). A sample item was "The people at my job really stick together." Social Support - Immediate Family. Six items that assessed the extent to which individuals' family members serve as sources of strength and guidance and are willing to offer tangible assistance were included (partially adapted from Turner, Finkelhor, \& Ormrod, 2010; from Zimet, Dahlem, Zimet, \& Farley, 1988). A sample item was "I can talk about my problems with my family." Social Support - Friends and Adults. Six items measured the extent to which individuals' friends and non-parent adults served as sources of strength and guidance 
(adapted from Turner et al., 2010). A sample item was "I can talk about my problems with my friends." Generous Behaviors. A 6-item scale that measured past year giving and everyday helping actions was included (adapted from Amato, 1990, Banyard et al., 2013). Items were dichotomous ("yes" or "no"). A sample item is "Spent time volunteering at a charity." Generative Roles. Nine items assessing mentoring or charitable roles served by the respondents and their parents (Hamby et al., 2015). Items were dichotomous ("yes" or "no"). A sample item is "At some time in my life, I have been a tutor."

\subsubsection{Physical health outcome was assessed as health-related quality of life}

Five items from the Healthy Days Measure used by the U.S. Centers for Disease Control and Prevention (2000) were used. For one item, participants rated their overall health ("excellent" to "poor"), and for the remaining items participants indicated how many days (approximately) during the past month a health item applied to them. A sample item was "During the past 30 days, for about how many days have you felt very healthy and full of energy?"

\subsection{Procedure}

Participants were recruited through a range of advertising techniques in order to allow us to reach segments of the population who are rarely included in psychological research. The majority of participants (75.2\%) were recruited at local community events, such as festivals and county fairs. Word-of-mouth was the second most productive recruitment strategy, accounting for $14.2 \%$ of participants. The remaining $10.6 \%$ were recruited through other strategies, including flyers, newspaper and radio ads, and direct mail. This region of Appalachia still has limited and often unreliable cellular and internet service; therefore, the survey software was specifically chosen to operate without internet connectivity on laptops and iPads. An audio option was available. Technical problems (such as iPads overheating) and time limitations prevented some individuals from completing the survey; overall, the completion rate was $85 \%$ and the median completion time was $53 \mathrm{~min}$. This is an excellent result by current survey standards, especially considering the survey length, with current completion rates often under 70\% (Abt SRBI, 2012) and sometimes under 50\% (Galesic \& Bosnjak, 2009). All participants received a $\$ 30$ Walmart gift card and information on local resources. All procedures were conducted in accordance with APA ethical principles and approved by the IRB of the study's home institution.

\section{Results}

In order to best assess resilience as the presence of healthy functioning and not simply the absence of problems, we created a measure of physical health related quality of life that represented above average functioning, or thriving. Participants were given a dichotomous score indicating whether or not they scored at least 0.5 standard deviations above the mean on the measure of perceived physical health. Table 2 presents the correlations among measures of strengths, adversity, and high health quality of life. As hypothesized, victimization and adversity were related to lower physical health quality. Nearly all of the strengths assessed were related to higher levels of perceived health related quality of life at the bivariate level. To 
determine which uniquely predicted good health related quality of life after accounting for exposure to adversity, we conducted a logistic regression analysis that included the measures of adversity and all of the strengths. Table 3 presents these findings. Age and gender were controlled for in the analysis. 


\section{Table 3. Logistic Regression of Health Related Quality of Life on Trauma, Adversity and Protective Factors.}

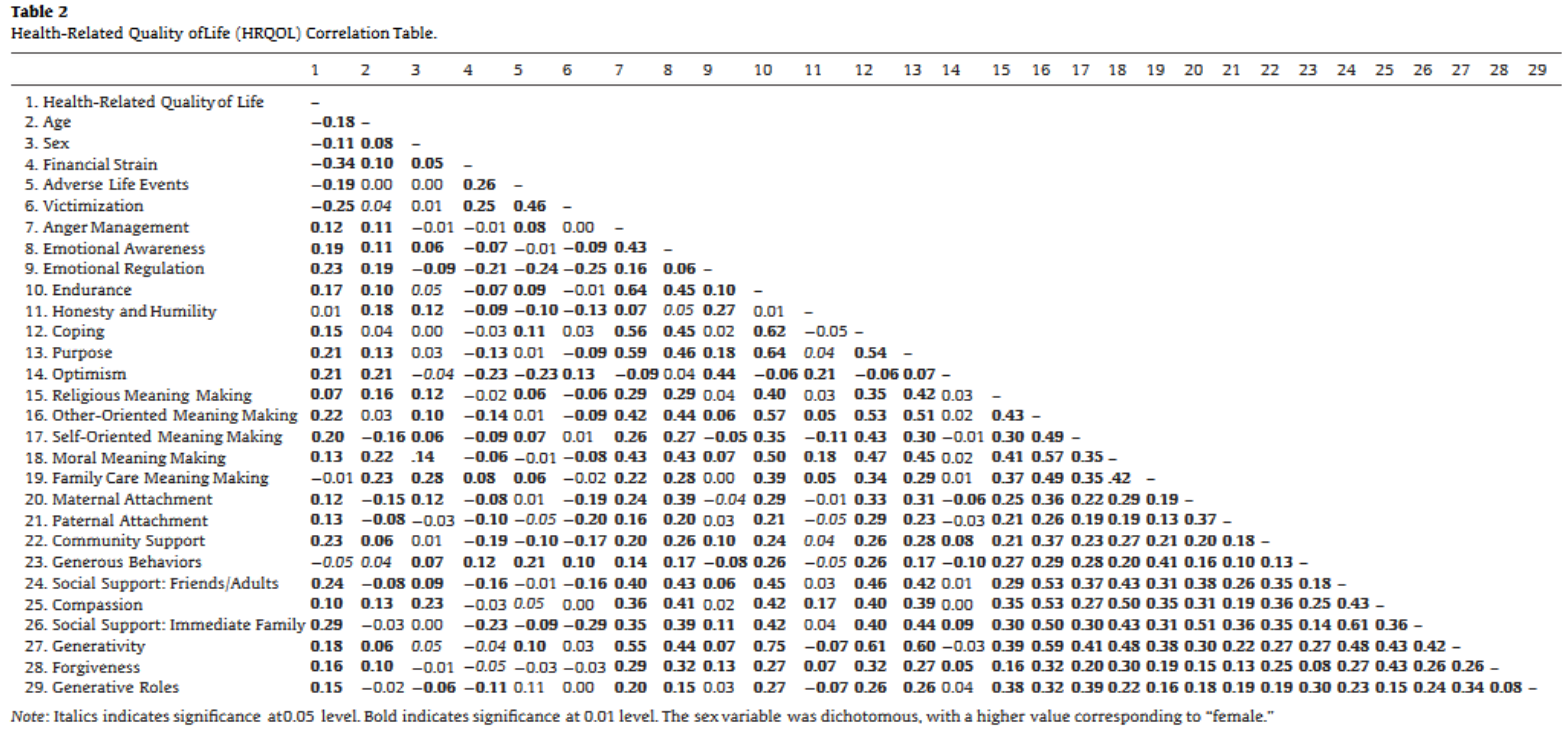

Table 3

Logistic Regression of Health Related Quality of Life on Trauma, Adversity and Protective Factors.

\begin{tabular}{|c|c|c|}
\hline$R^{2}=0.24$ & Odds Ratio & $95 \% \mathrm{CI}$ \\
\hline Emotional Regulation & $1.36^{+m}$ & $1.19-1.55$ \\
\hline Age & $0.98^{++m}$ & $0.97-0.99$ \\
\hline Financial Strain & $0.92^{++\infty}$ & $0.88-0.96$ \\
\hline Sex & $0.63^{++\infty}$ & $0.50-0.81$ \\
\hline Self-Oriented Meaning Making & $1.26^{+}$ & $1.10-1.45$ \\
\hline Community Support & $1.20^{+}$ & $1.05-1.36$ \\
\hline Victimization & $0.96^{*+}$ & $0.94-1.01$ \\
\hline Generous Behaviors & $0.81^{*+}$ & $0.71-0.92$ \\
\hline Moral Meaning Making & $1.19^{+}$ & $1.02-1.40$ \\
\hline Social Support: Friends/Adults & $1.18^{*}$ & $1.00-1.40$ \\
\hline Forgiveness & $1.15^{+}$ & $1.01-1.31$ \\
\hline Emotional Awareness & 1.14 & $0.99-1.33$ \\
\hline Optimism & 1.12 & $0.99-1.28$ \\
\hline Other-Oriented Meaning Making & 1.11 & $0.93-1.34$ \\
\hline Coping & 1.07 & $0.91-1.26$ \\
\hline Endurance & 1.05 & $0.86-1.29$ \\
\hline Purpose & 1.04 & $0.88-1.22$ \\
\hline Social Support: Immediate Family & 1.04 & $0.88-1.22$ \\
\hline Anger Management & 1.01 & $0.85-1.18$ \\
\hline Religious Meaning Making & 1.00 & $0.88-1.14$ \\
\hline Compassion & 1.00 & $0.85-1.19$ \\
\hline Generative Roles & 1.00 & $0.88-1.13$ \\
\hline Adverse Life Events & 0.98 & $0.93-0.98$ \\
\hline Maternal Attachment & 0.98 & $0.85-1.12$ \\
\hline Honesty and Humility & 0.97 & $0.85-1.10$ \\
\hline Family Care Meaning Making & 0.96 & $0.83-1.11$ \\
\hline Generativity & 0.95 & $0.79-1.15$ \\
\hline Paternal Attachment & 0.92 & $0.81-1.03$ \\
\hline
\end{tabular}

* Significant at 0.05 level.

- Significant at 0.01 level.

Significant at 0.001 level. 
Adversity was significantly related to a lesser likelihood of being in the positive health related quality of life category. Specifically, those reporting financial strain were $8 \%$ less likely to be thriving in their health related quality of life. Those who experienced more types of victimization before age 12 were $4 \%$ less likely to report good health related quality of life for each increase in strain or victimization, respectively. Increases in emotion regulation increased one's odds of positive health related quality of life by $36 \%$, the strongest association we observed. Meaning making, whether via following traditions and routines or by engaging in self-care activities like journaling and hobbies, increased the odds of positive health related quality of life by $19 \%$ and $26 \%$ respectively. Interpersonally, having more community support increased positive health related quality of life odds by $20 \%$ as did social support from friends (18\%) and practicing forgiveness in relationships (15\%). Interestingly, engaging in a high number of helping behaviors toward others was associated with a 19\% decreased odds of positive health related quality of life. Together, the combination of adversity and strengths explained one quarter of the variance in health related quality of life (Table 3 ).

\section{Discussion}

This study of a community sample from the rural Appalachian region of the United States, confirms earlier research about the lifelong burden of childhood victimization on physical health related quality of life. It highlights important intersections between physical and mental health for lifespan well-being. The findings are particularly striking because this is a relatively young, albeit also relatively financially disadvantaged, sample. However, the findings indicate that an array of strengths which can be promoted by mental health prevention and intervention strategies were associated with good physical health in this sample. These protective factors, represented in the Resilience Portfolio Model (Grych, Hamby, \& Banyard, 2015), contributed to health perceptions over and above the negative effects of trauma and adversity. Key strengths included skills in emotion regulation, meaning making, practicing forgiveness, and social support at the community and friend levels. Indeed, it may be that individuals who have strong emotion regulation skills despite adversity may be less likely to use tobacco or alcohol or to overeat as coping strategies, behaviors that increase risk for physical health problems. Meaning making practices may help individuals reframe adversities in ways that reduce stress and decrease pressure on emotion regulation systems. It is significant to highlight the prevalence of these strengths among a sample of individuals from a region of the United States that is more often characterized by stress and deficits than by strengths. The assets that were significant in promoting health fit well with research on the importance of values like self-reliance and community support that are often cited strengths of rural communities (Woodard, 2011). Further research on mechanisms of effects is needed but this exploratory study points out key next questions for the field.

Contrary to prediction, engaging in generous behaviors was associated with lower health quality of life. It may be that the measure of generosity used in the study, which included a number of items pertaining to generosity toward neighbors and friends, picked up on aspects of caregiver burden. Many of the adults in this sample of rural lower-income individuals were involved in taking care of younger or older family members, and it is possible that engaging in high levels of caregiving may have adverse effects on health. The Cronbach's alpha for this scale was also lower than for others. More measurement development is needed to perhaps 
separate out different forms of helping. Some forms of generous behaviors may be more of an indication of caregiver fatigue while others may be forms of helping that are more protective.

The current study represents an important first step in bridging knowledge of strengths and protective factors from the study of resilience and positive psychology with potential strength enhancing practices for mental and physical healthcare settings. It is limited by its cross sectional nature and the use of only one physical health outcome. Future research can build on these findings by assessing strengths over time, assessing family based strengths, and using a variety of physical health outcomes. This will enhance our understanding of physical health resilience. However, this study is one of the first studies of resilience among residents of rural Appalachia and one of the few studies to examine many different strengths concurrently.

A focus on the presence of positive strengths moves work on the consequences of childhood trauma forward. The findings provide a roadmap for factors that professionals working at the intersection of both mental and physical health can focus on in promoting physical health wellbeing even among populations who carry a high burden of adversity. Indeed, interventions from the field of positive psychology can work well in health care settings and expand individuals' access to mental health related strategies to promote well-being (Harris \& Thoresen, 2006). For example, mindfulness exercises designed to bring attention to internal thoughts and feelings are an effective way to promote emotion regulation (Baer, 2003; Grossman, Niemann, Schmidt, \& Walach, 2004; Keng, Smoski, \& Robins, 2011) and show promise with children (Diamond and Lee, 2011, Greenberg and Harris, 2012) and parents, particularly those parenting children with special needs (Benn, Akiva, Arel, \& Roeser, 2012).

Forgiveness is another strength that has been the focus of brief interventions (Fincham and Kashdan, 2004, Rye et al., 2005) which can be delivered individually or in groups (Wade, Hoyt, Kidwell, \& Worthington, 2014; Lundahl, Taylor, Stevenson, \& Roberts, 2008; Wade \& Worthington, 2005). Research suggests that interventions and training increase forgiveness and have mental health benefits for individuals and the present findings suggest that these benefits may extend to physical health as well (Wade et al., 2014). The present findings also suggest that encouraging meaning making and a sense of purpose could have beneficial effects on health. In particular, the meaning achieved through traditions and routines in one's life and through self-care pursuits including exercise, journaling, and hobbies was related to better physical health.

Finally, the importance of connections to others, established in the literature particularly for mental health, was confirmed in this sample in relation to physical health. Medical professionals can encourage individuals and families to find ways to get outside of themselves - to nurture connections. These findings support work (La Greca, Bearman, \& Moore, 2002; Wade et al., 2014) that documents the importance of social support for youth with medical problems. Others show links between social networks and health promoting behaviors such as healthy eating and exercise (Emmons, Barbeau, Gutheil, Stryker, \& Stoddard, 2007). Innovative methods are also being tried to enhance health by building community conversations among at-risk groups (Wang, Cash, \& Powers, 2000). Other research describes physical spaces like community gardens that can promote healthy behaviors as well as build 
sense of community (Comstock et al., 2010). These strategies may be particularly helpful in rural communities that already have strong values related to community helping.

There are a number of limitations to the current study. It represents only one geographical area. Rural communities are not all the same and given Ungar, 2013a, Ungar, 2013b and others' discussions of cultural variability in expressions of resilience, further research across different rural communities and regions of the United States and internationally are needed. Further, the current data are cross-sectional. While cross-sectional studies are an important tool in answering questions like those in the current study that have been under-researched because they allow for testing initial hypotheses in a dataset requiring fewer resources to collect, future research that follows individuals over time to examine resilient pathways longitudinally is needed. The findings point to the importance of integrating research on resilience more centrally into the field of violence research. The findings also help us understand health quality of life across the lifespan over and above childhood trauma. The resilience portfolio variables can be built into services and responses for survivors of child maltreatment to reduce the negative effects of trauma. They may also enhance the effectiveness of prevention strategies and provide examples of other variables to measure when assessing prevention program success.

\section{Funding source}

This project was made possible through the support of a grant from the John Templeton Foundation. The opinions expressed in this paper are those of the authors and do not necessarily reflect the views of the John Templeton Foundation.

\section{References}

1 Abt SRBI, Second national survey of children's exposure to violence (NatSCEV II): Methods report, Author, Silver Spring, MD (2012).

2 T.O. Afifi, H.L. MacMillan, Resilience following child maltreatment: A review of protective factors, The Canadian Journal of Psychiatry, 56 (5) (2011), pp. 266-272.

3 T.O. Afifi, N. Mota, H.L. MacMillan, J. Sareen, Harsh physical punishment in childhood and adult physical health, Pediatrics, 132 (2) (2013), pp. e333-e340, 10.1542/peds.2012-4021.

4 P.R. Amato, Personality and social network involvement as predictors of helpingbehavior in everyday life, Social Psychology Quarterly, 53 (1) (1990), pp. 31-43, 10.2307/2786867.

5 M.C. Ashton, K. Lee, The HEXACO-60: A short measure of the major dimensions of personality, Journal of Personality Assessment, 91 (4) (2009), pp. 340-345, 10.1080/00223890902935878.

6 R.A. Baer, Mindfulness training as a clinical intervention: A conceptual and empirical review, Clinical Psychology Science and Practice, 10 (2) (2003), pp. 125-143, 10.1093/clipsy/bpg015.

7 Trauma and physical health: Integrating trauma practice into primary care, V.L. Banyard, V. Edwards, K. Kendall-Tackett (Eds.), Routledge, London (2008). 
8 V. Banyard, S. Hamby, J. Grych, Life paths research measurement packet, Life Paths Research Program, Sewanee, TN (2013).

9 L.E. Benavides, Protective factors in children and adolescents exposed to intimate partner violence: An empirical research review, Child and Adolescent Social Work Journal, 32 (2) (2015), pp. 93-107.

10 R. Benn, T. Akiva, S. Arel, R.W. Roeser, Mindfulness training effects for parents and educators of children with special needs, Developmental Psychology, 48 (5) (2012), pp. 1476-1487, 10.1037/A0027537.

11 M.J. Briggs-Gowan, A.S. Carter, J.D. Ford, Parsing the effects violence exposure in early childhood: Modeling developmental pathways, Journal of Pediatric Psychology, 37 (1) (2012), pp. 11-22, 10.1093/jpepsy/jsr063.

12 Centers for Disease Control and Prevention, Measuring healthy days: Population assessment of health-related quality of life, CDC, Atlanta, GA (2000).

$13 \mathrm{D}$. Cicchetti, Annual research review: Resilient functioning in maltreated children?past, present, and future perspectives, Journal of child psychology and psychiatry, 54 (4) (2013), pp. 402-422.

14 N. Comstock, L.M. Dickinson, J.A. Marshall, M.J. Soobader, M.S. Turbin, M. Buchenau, J.S. Litt, Neighborhood attachment and its correlates exploring neighborhood conditions, collective efficacy, and gardening, Journal of Environmental Psychology, 30 (4) (2010), pp. 435-442, 10.1016/j.jenvp.2010.05.001.

15 A.L. Del Gaizo, J.D. Elhai, T.L. Weaver, Posttraumatic stress disorder, poor physical health and substance use behaviors in a national trauma-exposed sample, Psychiatry Research, 188 (2011), pp. 390-395.

$16 \mathrm{~A}$. Diamond, K. Lee, Interventions shown to aid executive function development in children 4 to 12 years old (vol 333, pg 959, 2011), Science, 334 (6054) (2011) [311311.

17 N.N. Duke, S.L. Pettingell, B.J. McMorris, I.W. Borowsky, Adolescent violence perpetration: Associations with multiple types of adverse childhood experiences, Pediatrics, 125 (4) (2010), pp. e778-e786, 10.1542/peds.2009-0597.

18 K.M. Emmons, E.M. Barbeau, C. Gutheil, J.E. Stryker, A.M. Stoddard, Social influences, social context, and health behaviors among working-class, multi-ethnic adults

19 Health Education \& Behavior, 34 (2) (2007), pp. 315-334, 10.1177/1090198106288011.

20 F.D. Fincham, T.B. Kashdan, Facilitating forgiveness: Developing group and community interventions, A.P. Linley, J. Stephen (Eds.), Positive psychology in practice, John Wiley \& Sons Inc., Hoboken, NJ, US (2004), pp. 617-637, xxii, 770 pp.

21 D. Finkelhor, S.L. Hamby, R. Ormrod, H. Turner, The juvenile victimization questionnaire: Reliability, validity, and national norms, Child Abuse \& Neglect, 29 (4) (2005), pp. 383-412, 10.1016/j.chiabu.2004.11.001.

22 D. Finkelhor, H. Turner, R. Ormrod, S.L. Hamby, Violence, abuse, and crime exposure in a national sample of children and youth, Pediatrics, 124 (5) (2009), pp. 1411-1423, 10.1542/peds.2009-0467. 
23 D. Finkelhor, H. Turner, S.L. Hamby, R. Ormrod, Polyvictimization: Children's Exposure to Multiple Types of Violence, Crime, and Abuse, National Survey of Children's Exposure to Violence (2011).

24 D. Finkelhor, A. Shattuck, H. Turner, S. Hamby, Improving the adverse childhood experiences study scale, JAMA Pediatrics, 167 (1) (2013), pp. 70-75.

25 D. Finkelhor, A. Shattuck, H.A. Turner, S.L. Hamby, The lifetime prevalence of child sexual abuse and sexual assault assessed in late adolescence, Journal of Adolescent Health, 55 (3) (2014), pp. 329-333.

26 E.G. Flaherty, R. Thompson, H. Dubowitz, E.M. Harvey, D.J. English, L.J. Proctor, D.K. Runyan, Adverse childhood experiences and child health in early adolescence, JAMA Pediatrics, 167 (7) (2013), pp. 622-629, 10.1001/jamapediatrics.2013.22

27 R.C. Fraley, N.G. Waller, K.A. Brennan, An item response theory analysis of self-report measures of adult attachment, Journal of Personality and Social Psychology, 78 (2) (2000), pp. 350-365.

$28 \mathrm{~W}$. Furman, D. Buhrmester, The network of relationships inventory: Behavioral systems version, International Journal of Behavioral Development, 33 (5) (2009), pp. 470-478.

29 M. Galesic, M. Bosnjak, Effects of questionnaire length on participation and indicators of response quality in a web survey, Public Opinion Quarterly, 73 (2) (2009), pp. 349360, 10.1093/poq/nfp031.

30 A.S. Garner, J.P. Shonkoff, B.S. Siegel, M.I. Dobbins, M.F. Earls, A.S. Garner, S.D.B. Pediat, Early childhood adversity toxic stress, and the role of the pediatrician: Translating developmental science into lifelong health, Pediatrics, 129 (1) (2012), pp. E224-E231, 10.1542/peds.2011-2662.

31 C. Gessert, S. Waring, L. Bailey-Davis, P. Conway, M. Roberts, J. Van Wormer, Rural definition of health: A systematic literature review, BMC Public Health, 15 (1) (2015), p. 1.

32 K.C. Gordon, D.H. Baucom, Forgiveness and marriage: Preliminary support for a measure based on a model of recovery from a marital betrayal, American Journal of Family Therapy, 31 (3) (2003), pp. 179-199, 10.1080/01926180390167188.

33 J.S. Gore, A. Sheppard, M. Waters, J. Jackson, R. Brubaker, Cultural differences in seeking mental health counseling: The role of symptom severity and type in Appalachian Kentucky, Journal of Rural Mental Health, 40 (1) (2016), p. 63.

34 K.L. Gratz, L. Roemer, Multidimensional assessment of emotion regulation and dysregulation: Development, factor structure, and initial validation of the difficulties in emotion regulation scale, Journal of Psychopathology and Behavioral Assessment, 26 (1) (2004), pp. 41-54, 10.1023/B:Joba.0000007455.08539.94.

35 M.T. Greenberg, A.R. Harris, Nurturing mindfulness in children and youth: Current state of research, Child Development Perspectives, 6 (2) (2012), pp. 161-166, 10.1111/j.1750-8606.2011.00215. x.

36 P. Grossman, L. Niemann, S. Schmidt, H. Walach, Mindfulness-based stress reduction and health benefits-A meta-analysis, Journal of Psychosomatic Research, 57 (1) (2004), pp. 35-43, 10.1016/S0022-3999(03)00573-7. 
37 J. Grych, S. Hamby, V. Banyard, The resilience portfolio model: Understanding healthy adaptation in victims of violence, Psychology of Violence, 5 (4) (2015), p. 343.

38 Grych, J., Hamby, S., \& Banyard, V. (in press) The Portfolio model of resilience: How positive psychology can inform the study of negative events. Psychology of Violence.

39 A.D. Hager, M.G. Runtz, Physical and psychological maltreatment in childhood and later health problems in women: An exploratory investigation of the roles of perceived stress and coping strategies, Child Abuse \& Neglect, 36 (5) (2012), pp. 393-403, 10.1016/i.chiabu.2012.02.002.

40 S. Hamby, H.A. Turner, D. Finkelhor, Financial strain index, Crimes Against Children Research Center, Durham, NH (2011).

41 S. Hamby, V.L. Banyard, J. Grych, Life paths research measurement packet, Life Paths Research Program, Sewanee, TN (2013).

42 S. Hamby, S.M. Stith, J. Grych, V.L. Banyard, The anger management scale: Brief trait version, Life Paths Research Program, Sewanee, TN (2013).

43 S. Hamby, L.A. Thomas, V. Banyard, E. de St. Aubin, J. Grych, Generative roles:

Assessing sustained involvement in generativity, American Journal of Psychology and Behavioral Sciences, 2 (2) (2015), pp. 24-32.

44 A.H. Harris, C.E. Thoresen, Extending the influence of positive psychology interventions into health care settings: Lessons from self-efficacy and forgiveness, The Journal of Positive Psychology, 1 (1) (2006), pp. 27-36.

45 D.G. Hegney, E. Buikstra, P. Baker, C. Rogers-Clark, S. Pearce, H. Ross, ..., A. WatsonLuke, Individual resilience in rural people: A Queensland study, Australia, Rural and Remote Health, 7 (14) (2007), pp. 1-13.

46 C.J. Holahan, R.H. Moos, Personal and contextual determinants of coping strategies, Journal of Personality and Social Psychology, 52 (5) (1987), pp. 946-955, 10.1037/0022-3514.52.5.946.

47 S.L. Keng, M.J. Smoski, C.J. Robins, Effects of mindfulness on psychological health: A review of empirical studies, Clinical Psychology Review, 31 (6) (2011), pp. 10411056, 10.1016/j.cpr.2011.04.006.

48 A.M. La Greca, K.J. Bearman, H. Moore, Peer relations of youth with pediatric conditions and health risks: Promoting social support and healthy lifestyles, Journal of Developmental and Behavioral Pediatrics, 23 (4) (2002).

49 B.D. Leipert, J.A. George, Determinants of rural women's health: A qualitative study in southwest Ontario, The Journal of Rural Health, 24 (2) (2008), pp. 210-218.

50 M. Lenzi, M.J. Furlong, E. Dowdy, J. Sharkey, G. Gini, G. Altoè, The quantity and variety across domains of psychological and social assets associated with school victimization, Psychology of Violence, 5 (4) (2015), p. 411.

51 J.S. Levin, K.S. Markides, L.A. Ray, Religious attendance and psychological well-being in Mexican Americans: A panel analysis of three-generations data, Gerontologist, 36 (4) (1996), pp. 454-463.

52 B.W. Lundahl, M.J. Taylor, R. Stevenson, K.D. Roberts, Process-based forgiveness interventions: A meta-analytic review, Research on Social Work Practice, 18 (5) (2008), pp. 465-478, 10.1177/1049731507313979. 
53 H.L. MacMillan, M. Tanaka, E. Duku, T. Vaillancourt, M.H. Boyle, Child physical and sexual abuse in a community sample of young adults: Results from the Ontario Child Health Study, Child Abuse \& Neglect, 37 (1) (2013), pp. 14-21.

$54 \mathrm{C}$. Marriott, C. Hamilton-Giachritsis, C. Harrop, Factors promoting resilience following childhood sexual abuse: A structured, narrative review of the literature, Child Abuse Review, 23 (2014), pp. 17-34, 10.1002/car.2258.

55 T. Maschi, J. Baer, M.B. Morrissey, C. Moreno, The aftermath of childhood trauma on late life mental and physical health: A review of the literature, Traumatology, 19 (2013), p. 49.

56 A.S. Masten, Global perspectives on resilience in children and youth, Child Development, 85 (2014), pp. 6-20.

57 D.P. McAdams, E. de St. Aubin, A theory of generativity and its assessment through self-report, behavioral acts, and narrative themes in autobiography, Journal of Personality and Social Psychology, 62 (6) (1992), pp. 1003-1015, 10.1037/00223514.62.6.1003.

58 M.E. McCullough, R.A. Emmons, J.A. Tsang, The grateful disposition: A conceptual and empirical topography, Journal of Personality and Social Psychology, 82 (1) (2002), pp. 112-127, 10.1037//0022-3514.82.1.112.

59 J.P. Merskya, J. Topitzesb, A.J. Reynolds, Impacts of adverse childhood experiences on health, mental health, and substance use in early adulthood: A cohort study of an urban, minority sample in the U.S, Child Abuse and Neglect, 37 (2013), pp. 917925.

60 R.E. Norman, M. Byambaa, R. De, A. Butchart, J. Scott, T. Vos, The long-term health consequences of child physical abuse, emotional abuse, and neglect: $A$ systematic review and meta-analysis, Plos Medicine, 9 (11) (2012).

61 R. Norton, Measuring marital quality-A critical-look at the dependent variable, Journal of Marriage and the Family, 45 (1) (1983), pp. 141-151, 10.2307/351302.

62 P.J. Obermiller, M.E. Maloney, The uses and misuses of Appalachian culture, Journal of Appalachian Studies, 22 (1) (2016), pp. 103-112.

63 K.I. Pargament, B.W. Smith, H.G. Koenig, L. Perez, Patterns of positive and negative religious coping with major life stressors, Journal for the Scientific Study of Religion, 37 (4) (1998), pp. 710-724, 10.2307/1388152.

64 K.I. Pargament, H.G. Koenig, L.M. Perez, The many methods of religious coping: Development anl initial validation of the RCOPE, Journal of Clinical Psychology, 56 (4) (2000), pp. 519-543, 10.1002/(Sici)1097-4679(200004)56:4<519:AidJclp6>3.0.Co;2-1.

65 E.A. Pommier, The compassion scale, Dissertation Abstracts International Section A: Humanities and Social Sciences, 72 (2011), p. 1174.

66 S. Putney, R. Middleton, Dimensions and correlated of religious ideologies, Social Forces, 39 (4) (1961), pp. 285-290.

67 C.M. Rennison, W.S. DeKeseredy, M. Dragiewicz, Intimate relationship status variations in violence against women urban, suburban, and rural differences, Violence Against Women, 19 (11) (2013), pp. 1312-1330, 10.1177/1077801213514487. 
68 L.T. Roberts, S. Hamby, J. Grych, V. Banyard, Beyond collective efficacy: New brief measures to assess the outer layers of the social ecology, American Journal of Psychology and Behavioral Sciences, 2 (2) (2015), pp. 14-23.

69 M.S. Rosenberg, N.D. Reppucci, Child Abuse. In Rural psychology, Springer, US (1983) pp. 305-336.

70 M.S. Rye, K.I. Pargament, W. Pan, D.W. Yingling, K.A. Shogren, M. Ito, Can group interventions facilitate forgiveness of an ex-spouse? A randomized clinical trial, Journal of Consulting and Clinical Psychology, 73 (5) (2005), pp. 880-892, 10.1037/0022-006x.73.5.880.

$71 \mathrm{C}$. Sabina, V. Banyard, Moving toward well-being: The role of protective factors in violence research, Psychology of Violence, 5 (4) (2015), p. 337.

72 R.J. Sampson, S.W. Raudenbush, F. Earls, Neighborhoods and violent crime: A multilevel study of collective efficacy, Science, 277 (5328) (1997), pp. 918-924, 10.1126/science.277.5328.918.

73 J. Sareen, C.A. Henriksen, S.L. Bolton, T.O. Afifi, M.B. Stein, ..., G.J.G. Asmundson, Adverse childhood experiences in relation to mood and anxiety disorders in a population-based sample of active military personnel, Psychological Medicine, 43 (2013), pp. 73-84.

74 M.F. Scheier, C.S. Carver, M.W. Bridges, Distinguishing optimism from neuroticism (and trait anxiety, self-mastery, and self-esteem)-A reevaluation of the life orientation test, Journal of Personality and Social Psychology, 67 (6) (1994), pp. 10631078, 10.1037/0022-3514.67.6.1063.

$75 \mathrm{~T}$. Schnell, Individual differences in meaning-making: Considering the variety of sources of meaning, their density and diversity, Personality and Individual Differences, 51 (5) (2011), pp. 667-673.

76 R. Sege, J. Linkenbach, Essentials for childhood: Promoting healthy outcomes from positive experiences, Pediatrics, 133 (6) (2014), pp. e1489-e1491, 10.1542/peds.2013-3425.

77 J.P. Shonkoff, A.S. Garner, The lifelong effects of early childhood adversity and toxic stress, Pediatrics, 129 (1) (2012), pp. e232-e246, 10.1542/peds.2011-2663.

78 J.P. Shonkoff, A.S. Garner, C.P.A.C. Fa, C.E.C.A. Depe, S.D.B. Pediat, The lifelong effects of early childhood adversity and toxic stress, Pediatrics, 129 (1) (2012), pp. e232-e246, 10.1542/peds.2011-2663.

79 S.M. Southwick, G.A. Bonanno, A.S. Masten, C. Panter-Brick, R. Yehuda, Resilience definitions, theory, and challenges: Interdisciplinary perspectives, European Journal of Psychotraumatology, 5 (2014).

80 Managing unwanted pursuit, B. Spitzberg, W. Cupach (Eds.), Sage, Thousand oaks, CA (2008).

81 S. Sprecher, B. Fehr, Compassionate love for close others and humanity, Journal of Social and Personal Relationships, 22 (5) (2005), pp. 629-651, $\underline{10.1177 / 0265407505056439}$. 
82 M.F. Steger, P. Frazier, S. Oishi, M. Kaler, The meaning in life questionnaire: Assessing the presence of and search for meaning in life, Journal of Counseling Psychology, 53 (1) (2006), pp. 80-93, 10.1037/0022-0167.53.1.80.

83 S.M. Stith, S. Hamby, The anger management scale: Development and preliminary psychometric properties, Violence and Victims, 17 (2002), pp. 383-402.

84 C.J. Tucker, D. Finkelhor, H. Turner, A. Shattuck, Association of sibling aggression with child and adolescent mental health, Pediatrics, 132 (1) (2013), pp. 79-84, 10.1542/peds.2012-3801.

$85 \mathrm{H}$. Turner, D. Finkelhor, R. Ormrod, Poly-victimization in a national sample of children and youth, American Journal of Preventive Medicine, 38 (3) (2010), pp. 323-330, 10.1016/j.amepre.2009.11.012.

86 H.A. Turner, D. Finkelhor, A. Shattuck, S. Hamby, Recent victimization exposure and suicidal ideation in adolescents, Archives of Pediatrics \& Adolescent Medicine, 166 (12) (2012), pp. 1149-1154, 10.1001/archpediatrics.2012.1549.

$87 \mathrm{H}$. Turner, A. Shattuck, S. Hamby, D. Finkelhor, Community disorder, victimization exposure, and mental health in a national sample of youth, Journal of Health and Social Behavior, 54 (2) (2013), pp. 257-274, 10.1177/0022146513479384.

88 U.S. Air ForceAir force community assessment survey: Survey data codebook, U.S. Air Force, Lackland Air Force Base, TX (2011).

89 M. UngarResilience, trauma, context, and culture, Trauma, Violence, \& Abuse, 14 (3) (2013), pp. 255-266.

$90 \mathrm{M}$. Ungar, Resilience after maltreatment: The importance of social services as facilitators of positive adaptation, Child Abuse \& Neglect, 37 (2) (2013), pp. 110-115.

91 N.G. Wade, E.L. Worthington, In search of a common core: A content analysis of interventions to promote forgiveness, Psychotherapy, 42 (2) (2005), pp. 160-177.

92 N.G. Wade, W.T. Hoyt, J.E.M. Kidwell, E.L. Worthington, Efficacy of psychotherapeutic interventions to promote forgiveness: A meta-analysis, Journal of Consulting and Clinical Psychology, 82 (1) (2014), pp. 154-170, 10.1037/A0035268.

93 C.C. Wang, J.L. Cash, L.S. Powers, Who knows the streets as well as the homeless? Promoting personal and community action through photovoice, Health Promotion Practice, 1 (1) (2000), pp. 81-89.

94 C.S. Widom, S.J. Czaja, T. Bentley, M.S. Johnson, A prospective investigation of physical health outcomes in abused and neglected children: New findings from a 30-year follow-up, American Journal of Public Health, 102 (6) (2012), pp. 1135-1144, 10.2105/Ajph.2011.300636.

$95 \mathrm{D}$. Wolfe, Risk and resilience in the context of child maltreatment: The way forward, Child Abuse and Neglect, 37 (2-3) (2013), pp. 90-92.

$96 \mathrm{C}$. Woodard, American nations: A history of the eleven rival regional cultures of North America, Penguin, New York (2011).

97 G.D. Zimet, N.W. Dahlem, S.G. Zimet, G.K. Farley, The multidimensional scale of perceived social support, Journal of Personality Assessment, 52 (1) (1988), pp. 3041. 